\title{
ДИАГНОСТИЧЕСКАЯ ЗНАЧИМОСТЬ ВЫЯВЛЕНИЯ LACTOВACILLUS SPP. В ЭЯКУЛЯТЕ
}

\author{
Д. Г. Почерников ${ }^{1 凶}$, Н. Т. Постовойтенко ${ }^{1}$ В. В. Гетьман ${ }^{1}$, И. С. Галкина
}

Ивановская государственная медицинская академия, Иваново, Россия

${ }^{2}$ Центральный научно-исследовательский институт организации и информатизации здравоохранения, Москва, Россия

В последние годы благодаря внедрению метода полимеразной цепной реакции в реальном времени (ПЦР-РВ) значительно расширился спектр микроорганизмов, выявляемых в мочеполовом тракте мужчин, детализировано представление о структуре бактериальных компонентов микробиома. Одной из наименее изученных групп микроорганизмов остается Lactobacillus spp. При ведении пациентов с репродуктивными нарушениями авторами накоплен клинический опыт, демонстрирующий возможную взаимосвязь изменения уровня половых гормонов и основных показателей спермограммь с наличием Lactobacillus spp. в эякуляте. Целью работы было сравнить уровни лютеинизирующего гормона, фолликулостимулирующего гормона, тестостерона, эстрадиола, пролактина, прогестерона, а также глобулина, связывающего половые гормоны (ГСПГ), в сыворотке крови и изменения показателей спермограммы у 210 мужчин при выявлении в эякуляте Lactobacillus spp. и при их отсутствии. В основную группу были включены 105 мужчин, в эякуляте которых по данным ПЦР-РВ выявлены Lactobacillus spp. в количестве (Lg) $\geq 10^{3}$. Контрольная группа включала 105 мужчин, у которых отсутствовали Lactobacillus spp. и структура бактериального компонента микробиома эякулята соответствовала норме. В основной группе по сравнению с контрольной у мужчин чаще встречались гормональные нарушения: отклонение от нормы уровней трех и более гормонов ( $p$ = 0,04), гиперэстрадиолемия ( $p=0,05)$ и повышение уровня ГСПГ ( $p=0,01)$. Установлено, что наличие Lactobacillus spp. в эякуляте мужчин основной группь ассоциировано с олигоастенотератозооспермией ( $p<0,01)$, со снижением концентрации сперматозоидов $(p=0,01)$, с ухудшением их подвижности ( $>$ < 0,01) и нарушением морфологии ( < 0,01). Таким образом, присутствие в эякуляте Lactobacillus spp. может служить дополнительным маркером нарушения гормонального фона и фертильности у мужчин.

Ключевые слова: Lactobacillus spp., лактобактерии, эякулят, мужское бесплодие, микрофлора эякулята, «Андрофлор», патоспермия, олигоастенотератозооспермия, гиперэстрадиолемия, гиперпрогестеронемия

Вклад авторов: Д. Г. Почерников - планирование исследования, анализ литературы, интерпретация и анализ данных, подготовка черновика рукописи, подготовка финального варианта статьи; Н. Т. Постовойтенко - анализ литературы, сбор, анализ и интерпретация данных, подготовка черновика рукописи, подготовка финального варианта статьи; В. В. Гетьман - сбор, анализ и интерпретация данных, подготовка черновика рукописи; И. С. Галкина - планирование исследования, интерпретация данных, подготовка черновика рукописи, подготовка финального варианта статьи.

Соблюдение этических стандартов: работа одобрена этическим комитетом Ивановской государственной медицинской академии и является фрагментом начатого ранее исследования (протокол № 5 от 03 июня 2009 г.). Все пациенты подписали добровольное информированное согласие на участие в исследовании.

$\square$ Для корреспонденции: Денис Геннадьевич Почерников

Шереметевский проспект, д. 8, г. Иваново, 153012; urologkmn@mail.ru

Статья получена: 29.05.2020 Статья принята к печати: 17.06.2020 Опубликована онлайн: 29.06.2020

DOI: $10.24075 /$ vrgmu.2020.039

\section{DIAGNOSTIC SIGNIFICANCE OF LACTOBACILLUS SPP. IDENTIFICATION IN EJACULATE}

Pochernikov DG ${ }^{1 \otimes}$, Postovoytenko NT'1, Getman VV', Galkina IS ${ }^{2}$

${ }^{1}$ Ivanovo State Medical Academy, Ivanovo, Russia

${ }^{2}$ Federal Research Institute for Health Organization and Informatics, Moscow, Russia

Popularization of the real-time polymerase chain reaction method (RT-PCR), which is a trend of the recent years, allowed to significantly expand of the range of microorganisms that can be detected in the genitourinary tract of men. Moreover, the available picture of the microbiome's bacterial component structure became more detailed. Lactobacillus spp. remains one of the least studied groups of microorganisms. Treating patients with reproductive disorders, the authors have accumulated clinical experience demonstrating the possible relationship between presence of Lactobacillus spp. in the ejaculate and changes in the level of sex hormones and the key values registered with a spermogram. This study aimed to compare the levels of luteinizing hormone, follicle-stimulating hormone, testosterone, estradiol, prolactin, progesterone, and sex hormone binding globulin (SHBG) in blood serum and changes in spermogram values in 210 men with and without Lactobacillus spp. detected in their ejaculate. The treatment group included 105 men whose ejaculate had Lactobacillus spp. in the amount of (Lg) $\geq 10^{3}$, as detected by RT-PCR. The control group included 105 men whose ejaculate did not have Lactobacillus spp. detected; the microbiome's bacterial component structure of their ejaculate was normal. Compared to the control group, treatment group had hormonal disorders registered more often: abnormal levels of three or more hormones $(p=0.04)$, hyperestradiolemia $(p=0.05)$, increased level of SHBG $(p=0.01)$. It was established that the presence of Lactobacillus spp. in the ejaculate of treatment group participants is associated with oligoastenoteratozoospermia $(p<0.01)$, decreased concentration of spermatozoa $(p=0.01)$, their decreased motility $(p<0.01)$ morphology abnormalities $(p<0.01)$. Thus, the presence of Lactobacillus spp. in the ejaculate can be interpreted as an additional marker of hormonal imbalance and fertility dysfunction in men.

Keywords: Lactobacillus spp., lactobacilli, ejaculate, male infertility, ejaculate microflora, Androflor, pathospermia, oligoastenoteratozoospermia, hyperestradiolemia, hyperprosterolemia

Author contribution: Pochernikov DG — research planning, literature analysis, data interpretation and analysis, manuscript drafting, preparation of the final version of the article; Postovoytenko NT — literature analysis, data collection, analysis and interpretation, manuscript drafting, preparation of the final version of the article; Getman W - data collection, analysis and interpretation, manuscript drafting; Galkin IS — research planning, data interpretation, manuscript drafting, preparation of the final version of the article.

Compliance with ethical standards: the study was approved by the Ivanovo State Medical Academy ethics committee and is a part of the earlier research (protocol № 5 of June 03, 2009). All patients signed a voluntary informed consent to participate in the study.

$\bowtie$ Correspondence should be addressed: Denis G. Pochernikov

Sheremetevsky prospekt, 8, Ivanovo, 153012; urologkmn@mail.ru

Received: 29.05.2020 Accepted: 17.06.2020 Published online: 29.06.2020

DOI: $10.24075 / \mathrm{brsmu} .2020 .039$ 
В настоящее время исследователи не пришли к единому мнению, какой состав микрофрлоры урогенитального тракта мужчин считать нормальным [1]. По данным клинических рекомендаций последних лет, пациентам с бесплодием или проходящим прегравидарную подготовку рекомендовано проводить только культуральный анализ эякулята [2-4]. Однако этот метод не в полной мере отражает особенности урогенитальной микробиоты мужчины, так как не позволяет идентисицировать некультивируемые микроорганизмы, например облигатноанаэробные и некоторые факультативно-анаэробные, в том числе лактобактерии [5, 7-10]. По мнению ведущих европейских и российских урологов, с целью диагностики простатита необходимо использовать двухстаканную пробу и дополнительно исследовать эякулят не только бактериологическим методом, но и методом полимеразной цепной реакции в реальном времени (ПЦР-РВ) [3, 5, 7-10]. В последние годы благодаря внедрению современных методов диагностики был значительно расширен спектр выявляемых микроорганизмов в урогенитальном тракте мужчин и женщин [1, 8, 11-13]. На наш взгляд, одним из перспективных методов является ПЦР-РВ с применением теста «Андрофлор» у мужчин, позволяющий не только качественно, но и количественно оценить все основные группы бактерий микробиоты эякулята, включая лактобактерии [5, 7, 9, 10, 14-19].

В литературе имеются единичные публикации о встречаемости лактобактерий в различных биотопах мочеполового тракта мужчин. По данным ряда авторов [16, 19, 20], Lactobacillus spp. - одни из часто встречающихся микроорганизмов как у здоровых мужчин, так и у пациентов с уретритом или простатитом, идентифицируемые бактериологическим методом [21], секвенированием 16S pPHК [6, 20] и ПЦР-PВ [5, 8, 14, 16, 19]. Так, Lactobacillus spp. были обнаружены в 9-73,3\% случаев в микробиоте эякулята у мужчин с бесплодием или проходивших обследование с целью прегравидарной подготовки [5, 6, 8, 16]. Представляет большой интерес исследование, в котором была выявлена статистически значимая корреляция между наличием лактобактерий в уретре и гормональных дизрапторов в семенной жидкости у мужчин с бесплодием [19].

Имеются работы, указывающие на связь между присутствием в эякуляте лактобактерий и нормальными показателями спермограммы. Так, показано увеличение относительного содержания Lactobacillus spp. в образцах спермы с нормальной морфологией сперматозоидов [22]. Обнаружена положительная корреляционная связь между присутствием лактобактерий в сперме и нормальными показателями спермограммы у мужчин [23].
Наименее изучены на сегодняшний день Lactobacillus spp., выявленные у мужчин, которые соблюдали правила взятия биоматериала, а именно половое воздержание или барьерную контрацепцию, с целью снижения риска попадания лактобактерий из влагалища. По мнению ряда авторов, Lactobacillus spp. в большинстве случаев транзиторная микросрлора мочеполового тракта у мужчин $[7,10,14,17]$. Лактобактерии могут играть роль вероятного микробного агента, способствующего возникновению и поддержанию хронического воспаления в предстательной железе [24]. В последние годы все чаще обсуждают роль гормональных изменений, в частности, влияние уровня тестостерона на бактериальную обсемененность секрета предстательной железы [25, 26]. Но при анализе доступной нам литературы мы не обнаружили данных о взаимосвязи основных репродуктивно значимых гормонов эстрадиола, пролактина, прогестерона, а также ГСПГ, традиционно входящих в алгоритм обследования мужчин с репродуктивными нарушениями [2-4], с инфекционными агентами, выявленными в секрете простаты или эякуляте.

По результатам проведенного пилотного исследования, нами получен патент на изобретение [27]. Суть открытия заключается в том, что присутствие в эякуляте Lactobacillus spp. в титре $(\mathrm{lg}) \geq 10^{3}$ может служить дополнительным маркером гормональных нарушений и основанием для дальнейшего расширенного обследования мужчины. В связи с высокой встречаемостью лактобактерий и отсутствием данных о их влиянии у мужчин на фертильные свойства спермы, тема данного исследования чрезвычайно актуальна. Целью работы было провести сравнительный анализ изменения уровней ЛГ, ФСГ, тестостерона, эстрадиола, пролактина, прогестерона, ГСПГ в сыворотке крови и основных показателей спермограммы у мужчин при выявлении в эякуляте Lactobacillus spp. и при их отсутствии.

\section{ПАЦИЕНТЫ И МЕТОДЫ}

Проведено сравнительное проспективное исследование 210 мужчин с ноября 2016 по июль 2019 г., обратившихся в урологическую клинику Ивановской государственной медицинской академии по поводу бесплодия, проходящих прегравидарную подготовку, и/или с сопутствующей эректильной дисфункцией. Критерии включения пациентов в исследование: мужчины репродуктивного возраста; наличие бесплодия или проведение прегравидарной подготовки; все обследуемые пациенты в течение последних четырех недель не должны были получать гормональные и антибактериальные препараты, а также какие-либо другие лекарственные средства. Критерии исключения из исследования: наличие гипогонадотропного и

Таблица 1. Уровень исследуемых гормонов в двух сравниваемых группах

\begin{tabular}{|l|c|c|c|c|}
\hline Гормон в сыворотке крови & $\begin{array}{c}\text { Референсные } \\
\text { значения }\end{array}$ & $\begin{array}{c}\text { Группа мужчин с Lactobacillus spp. } \\
(n=105), \text { среднее значение } \pm \text { станд. откл. }\end{array}$ & $\begin{array}{c}\text { Группа мужчин без лактобактерий } \\
(n=105), \text { среднее значение } \pm \text { станд. откл. }\end{array}$ & $p$ \\
\hline ЛГ, мМЕ/мл & $1-12$ & $5,1 \pm 2,1$ & $4,4 \pm 2,0$ & 0,09 \\
\hline ФСГ, мМЕ/мл & $0,9-12$ & $5,2 \pm 2,5$ & $4,5 \pm 2,7$ & 0,1 \\
\hline Пролактин, нг/мл & $4-15$ & $14,1 \pm 7,8$ & $12,8 \pm 5,9$ & 0,3 \\
\hline Прогестерон, нг/мл & $0,05-0,15$ & $0,23 \pm 0,14$ & $0,25 \pm 0,17$ & 0,3 \\
\hline Эстрадиол, пг/мл & $11-43$ & $26,5 \pm 13,5$ & $23,4 \pm 9,9$ & 0,04 \\
\hline Тестостерон, нг/мл & $3,5-9$ & $5,3 \pm 2,6$ & $5,1 \pm 2,5$ & 0,2 \\
\hline ГСПГ, нмоль/л & $18-54$ & $41,1 \pm 23,2$ & $35,8 \pm 20,7$ & 0,08 \\
\hline ИСА, \% & $15-102$ & $51,6 \pm 23,3$ & $51,3 \pm 27,6$ & 0,5 \\
\hline ТЭИ & Не менее 83 & $232,8 \pm 134,4$ & $252 \pm 157,1$ & 0,2 \\
\hline
\end{tabular}




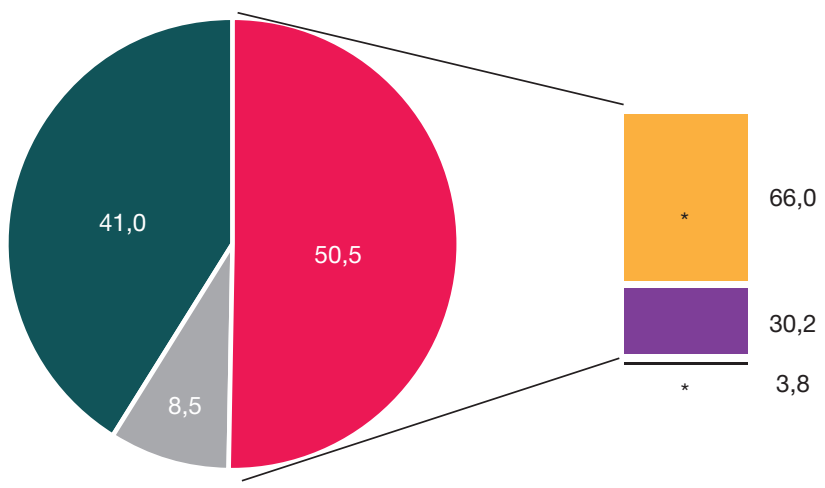

Изменение уровня одного гормона

Изменение уровня более чем одного гормона

В пределах референсных значений
Изменение уровня трех гормонов

Изменение уровня двух гормонов

Изменение уровня четырех гормонов

Pис. 1. Гормональные изменения в группе мужчин с Lactobacillus spp., $n=105$

гипергонадотропного гипогонадизма, сахарного диабета, гипо- и гипертиреоза; наличие инфекций, передающихся половым путем, и клинических проявлений простатита, таких как боль и дизурия; наличие аномалий кариотипа, мутации в гене CFTR, микроделеций в AZF-локусе Ү-хромосомы.

Всем мужчинам проводили исследование эякулята методом ПЦР-РВ с использованием теста «Андрофлор», а также определяли в сыворотке венозной крови уровни лютеинизирующего гормона (ЛГ), фолликулостимулирующего гормона (ФСГ), общего тестостерона, эстрадиола, пролактина, прогестерона и глобулина, связывающего половые гормоны (ГСПГ), индекса свободных андрогенов (ИСА), тестостеронэстрадиолового индекса (ТЭИ), которые общеприняты к назначению при обследовании мужчин, страдающих бесплодием или проходящих прегравидарную подготовку [2, 3]. Забор крови на исследование концентрации гормонов проводили с 8 до 10 ч утра натощак, также необходимым условием было половое воздержание в течение суток.

Bce мужчины были разделены на две группы, рандомизированные по возрасту, индексу массы тела, приему алкоголя и табакокурению, предъявляемым жалобам, установленному диагнозу и уровню сывороточного тестостерона, с целью исключения влияния последнего на обсемененность эякулята $[25,26]$. В основную группу вошли 105 пациентов, у которых по результатам ПЦР-PВ эякулята обнаружены Lactobacillus spp. в титре $(\mathrm{Lg}) \geq 10^{3}$. Контрольную группу составили 105 мужчин, у которых отсутствовали Lactobacillus spp. и структура бактериальной составляющей микробиоты эякулята соответствовала норме по заключению теста «Андрофлор». Средний возраст пациентов первой группы составил 35,5 \pm 8,1 лет, второй $-35,8 \pm 8,3$ ( $p>0,05)$. Перед забором биоматериала пациенты предварительно мочились, проводили тщательный туалет наружных половых органов без применения антисептиков и собирали эякулят методом мастурбации в стерильный контейнер из полимерного материала. Контейнеры доставляли в лабораторию в течение не более одного часа с момента взятия.

Для выполнения ПЦР-РВ использовали детектирующий амплификатор ДТ-96 («ДНК-Технология»; Россия) [28] и наборы реагентов «Андрофрлор» (регистрационное удостоверение на медицинское изделие РЗН 2016/4490 от 25.07.2016). Для исследования уровня гормонов с 8 до 10 ч утра в асептических условиях производили взятие венозной крови в пробирки объемом 5 мл.

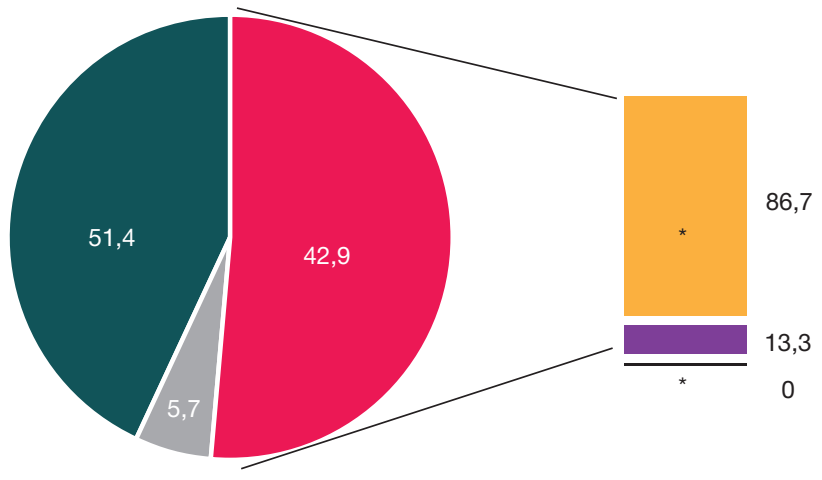

Изменение уровня одного гормона

Изменение уровня более чем одного гормона

В пределах референсных значений
Изменение уровня трех гормонов

Изменение уровня двух гормонов

Изменение уровня четырех гормонов

Рис. 2. Гормональные изменения в группе мужчин без лактобактерий, $n=105$ 


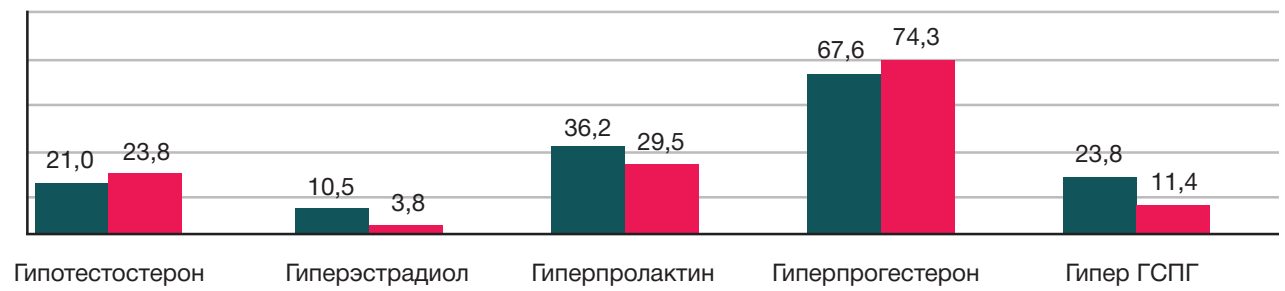

Группа мужчин с Lactobacillus spp., $n=105$

Группа мужчин с нормофлорой, $n=105$

Рис. 3. Изменения исследуемых гормонов в сравниваемых группах

После свертывания жидкую часть переносили в чистые стерильные пробирки, центрифугировали на лабораторной центрифуге 10 мин при 1500 об./мин, затем надосадочную жидкость переносили в одноразовые пластиковые пробирки типа Эппендорф. Уровень гормонов определяли с помощью аналитической системы Roche Cobas e8000 602, (Roche Diagnostics; Швейцария). Референсные значения исследуемых гормонов представлены в табл. 1. Исследование эякулята выполняли с использованием анализатора SQA-V (Medical Electronic System Ltd.; Израиль). Количество лейкоцитов в сперме определяли путем приготовления и окрашивания мазков с использованием красителей Leukodif 200 (Erba Lachema; Чехия), при исследовании оценивали количественные и качественные показатели по нормам WHO (2010 г.) [29]. Статистический анализ проводили с использованием пакета прикладных программ Microsoft Excel 2013 и Statistica 12.0 (Stat Soft Inc.; США). Достоверность полученных данных анализировали с помощью критериев Уилкоксона и Фишера, различия считали достоверными при $p \leq 0,05$.

\section{РЕЗУЛЬТАТЫ ИССЛЕДОВАНИЯ}

В группе пациентов с Lactobacillus spp. уровни всех исследуемых гормонов соответствовали референсным значениям у 9 (8,5\%) мужчин, в контрольной группе у $6(5,7 \%)$ (p > 0,05). Комбинированные гормональные нарушения у мужчин в основной группе встречались чаще (50,5\% против 42,9\%; $p$ > 0,05), чем в группе без лактобактерий (рис. 1 и 2 соответственно), при этом статистически значимо чаще у мужчин с лактобактериями отмечались более выраженные гормональные нарушения в виде отклонений от нормы уровней трех и более гормонов $(p=0,04)$.

В табл. 1 представлены средние значения уровней гормонов в двух исследуемых группах. Группа мужчин с Lactobacillus spp. статистически значимо по сравнению с контрольной отличалась по среднему уровню эстрадиола, у них выявлена также тенденция к повышению уровней пролактина и ГСПГ. Статистически значимо чаще в основной группе встречались гиперэстрадиолемия (10,5\% против $3,8 \% ; p=0,05)$ и повышение уровня ГСПГ $(23,8 \%$ против $11,4 \% ; p=0,01)$. По остальным исследуемым гормонам статистически значимых различий выявлено не было, но наблюдалась тенденция к более частой встречаемости гиперпролактинемии в группе с лактобактериями (рис. 3).

Обсемененность эякулята, определяемая как общая бактериальная масса (ОБМ), была выше в группе мужчин c Lactobacillus spp., по сравнению с контрольной группой

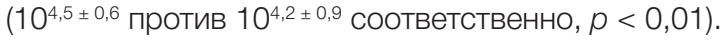

По результатам ПЦР-РВ (рис. 4), в основной группе достоверно чаще, чем в группе без лактобактерий, обнаруживали большинство идентифицируемых микроорганизмов $(p<0,05)$.

По результатам спермиологического исследования (рис. 5), в основной группе более выражены нарушения в виде олигоастенотератозооспермии (30,0\% против 9,3\%; $p<0,01)$ и астенотератозооспермии $(28,8 \%$ против $20,0 \% ; p=0,1)$. В контрольной группе достоверно чаще выявляли нормозооспермию (42,7\% против 25,0\%; $p=0,01)$

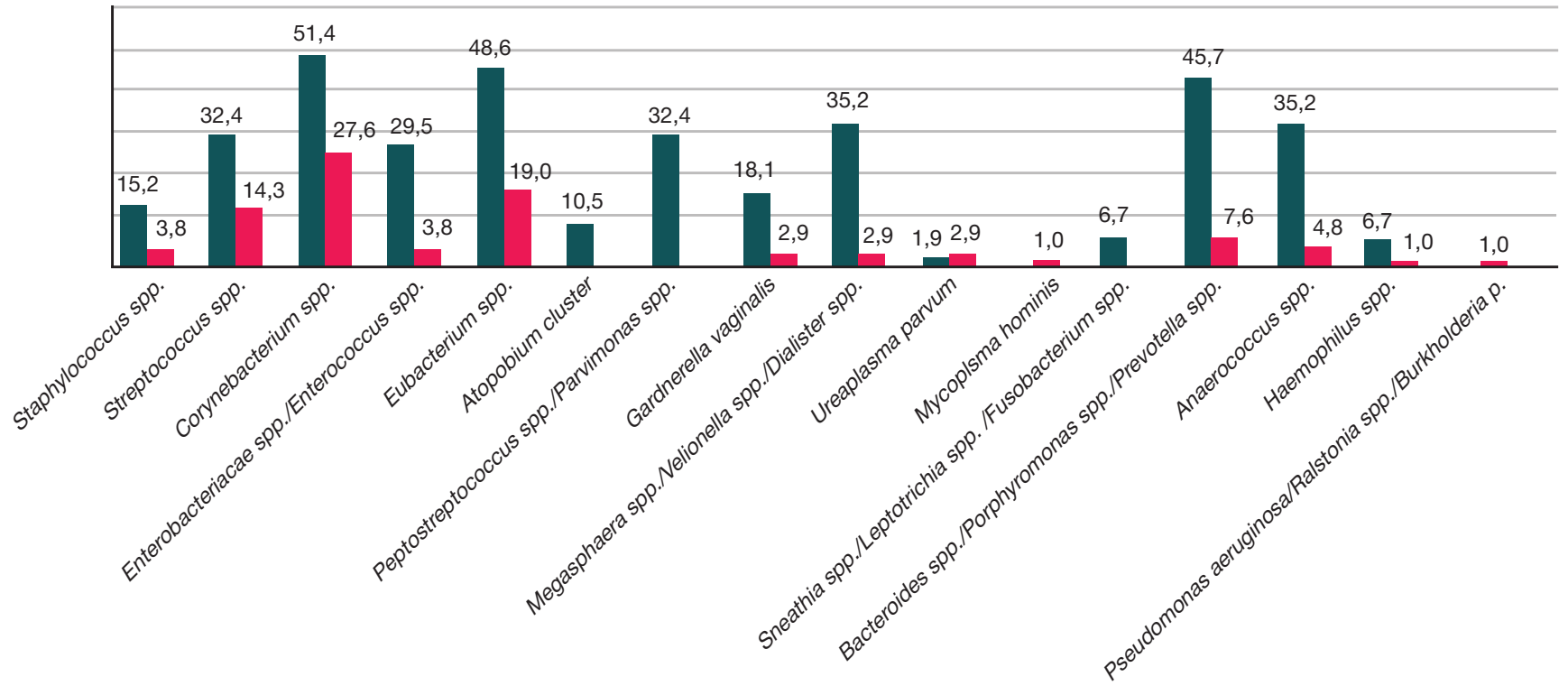

Группа мужчин с Lactobacillus spp., $n=105$

Группа мужчин с нормофлорой, $n=105$

Рис. 4. Частота встречаемости микроорганизмов в эякуляте по данным ПЦР-РВ в двух сравниваемых группах 


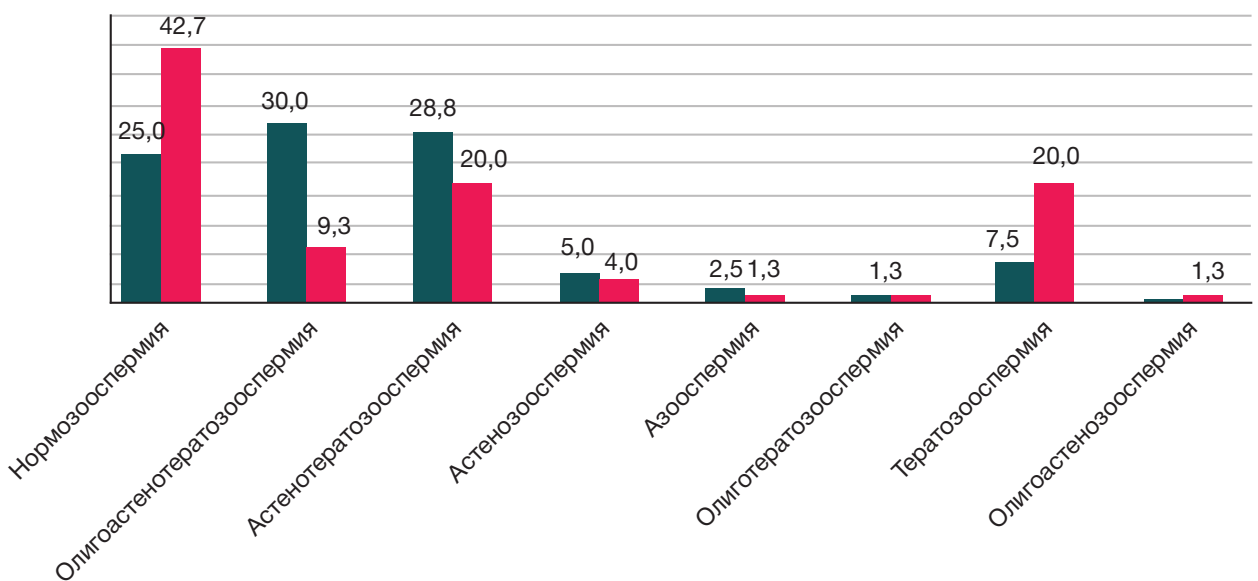

Группа мужчин с Lactobacillus spp., $n=80$

Контрольная группа, $n=75$

Рис. 5. Изменения в параметрах спермограммы в двух сравниваемых группах

и изолированную тератозооспермию (20,0\% против 7,5\%; $p=0,01)$, а также в два раза чаще встречалась бессимптомная лейкоспермия (26,7\% против 13,8\%; $p=0,03)$. При анализе основных показателей спермограммы (табл. 2) у мужчин с лактобактериями концентрация, подвижность и морфология сперматозоидов были статистически значимо хуже по сравнению с мужчинами контрольной группы.

\section{ОБСУЖДЕНИЕ РЕЗУЛЬТАТОВ}

Есть мнение, что лактобактерии у мужчин могут присутствовать только как транзиторная флора. Однако в клинической практике встречаются пациенты с Lactobacillus spp. в эякуляте, у которых период полового воздержания составлял более одного месяца или они всегда использовали барьерную контрацепцию, что минимизирует транзиторный характер присутствия этих бактерий. В данной работе, в отличие от первоначальных результатов пилотного исследования [27], подтвердилась гипотеза о связи гиперэстрадиолемии и появлении Lactobacillus spp. в эякуляте. Лейкоспермия встречалась в основной группе реже, чем в контрольной группе мужчин без лактобактерий, что, вероятно, связано с часто встречающимися случаями обструкции или фиброза ацинусов предстательной железы [30]. Нами выявлена большая бактериальная обсемененность эякулята у мужчин в основной группе, по сравнению с контрольной группой $(p<0,05)$, что может быть объяснено гиперэстрадиолемией, повышением уровня ГСПГ и пролактина, так как последние снижают биологическую активность тестостерона. Один из механизмов повышения
ГСПГ связан с повышением эстрадиола в крови и часто отражает «скрытую гиперэстрадиолемию», т. е. в пределах референсных значений показателей. Повышенный уровень лактобактерий можно рассматривать как защитнокомпенсаторный механизм поддержания нормального микробиома эякулята, предотвращающего инвазию половых путей условно-патогенными микроорганизмами [6, 21, 23].

По нашему мнению, при условии строгого соблюдения правил подготовки к исследованию эякулята методом ПЦР-РВ, таких как половое воздержание или барьерная контрацепция не менее трех суток, выявление Lactobacillus spp. в титре $\mathrm{Lg} \geq 10^{3}$ может быть дополнительным поводом к определению уровня эстрадиола, пролактина, прогестерона и ГСПГ.

Анализ полученных данных не позволяет провести корректную оценку негативной или позитивной роли лактобактерий в эякуляте и может стать задачей дальнейших исследований, при проведении которых с использованием технологии ПЦР-РВ можно будет установить количество Lactobacillus spp. и провести типирование данной группы микроорганизмов.

\section{ВЫВОДЫ}

Таким образом, Lactobacillus spp. чаще встречаются в эякуляте у мужчин с гиперэстрадиолемией и более тяжелыми сочетанными нарушениями в спермограмме. Обнаружение Lactobacillus spp. в сперме может служить дополнительным маркером нарушения гормонального фона у мужчины, даже при нормальных показателях спермограммы.

Таблица 2. Исследуемые показатели спермограммы в двух сравниваемых группах

\begin{tabular}{|l|c|c|}
\hline \multicolumn{1}{|c|}{ Показатель спермограммы } & $\begin{array}{c}\text { Группа мужчин с Lactobacillus spp. } \\
(n=80), \text { среднее значение } \pm \text { станд. откл. }\end{array}$ & $\begin{array}{c}\text { Группа мужчин без лактобактерий ( } n=75), \\
\text { среднее значение } \pm \text { станд. откл. }\end{array}$ \\
\hline Концентрация сперматозоидов, млн/мл & $52,6 \pm 44,8$ & $70,1 \pm 48,2$ \\
\hline Общее кол-во сперматозоидов в эякуляте, млн & $167,1 \pm 167,3$ & $221,6 \pm 169,4$ \\
\hline Прогрессивно-подвижные сперматозоиды (PR), \% & $25,4 \pm 23,7$ & $40,4 \pm 23,7$ \\
\hline $\begin{array}{l}\text { Непрогрессивно-подвижные сперматозоиды, } \\
\text { (NP), \% }\end{array}$ & $11,3 \pm 9,4$ & $12,3 \pm 9,7$ \\
\hline Неподвижные сперматозоиды, (IM), \% & $61,2 \pm 27,8$ & $<, 01$ \\
\hline Нормальные формы, \% & $2,4 \pm 2,1$ & $46,8 \pm 23,5$ \\
\hline
\end{tabular}


1. Чаплин А. В., Ребриков Д. В., Болдырева М. Н. Микробиом человека. Вестник РГМУ. 2017; (2): 5-13. DOI: 10.24075/ brsmu.2017-02-01.

2. Jungwirth JA, Diemer T, Kopa Z, et. al. EAU guidelines on male infertility (c) European Association of Urology. Available from: https://uroweb.org/wp-content/uploads/EAU-Guidelines-onMale-Infertility-2019.pdf (Accessed May 2, 2019).

3. Щеплева П. А., редактор. Андрология для урологов. М. Медфорум-Альфа, 2019; 424 с.

4. Аляев Ю. Г., Глыбочко П. В., Пушкарь Д. Ю., редакторы. Урология: Российские клинические рекомендации. М.: Медфорум, 2018; 544 c.

5. Почерников Д. Г., Витвицкая Ю. Г., Болдырева М. Н., Галкина И. С Информативность биоматериала для исследования микробиоть урогенитального тракта мужчин методом ПЦР-РВ (пилотное исследование). Экспериментальная и клиническая урология. 2019; 2: 128-32. DOI: 10.29188/2222-8543-2019-11-2-128-132.

6. Monteiro C, Marques PI, Cavadas B, et al. Characterization of microbiota in male infertility cases uncovers differences in seminal hyperviscosity and oligoasthenoteratozoospermia possibly correlated with increased prevalence of infectious bacteria. Am $J$ Reprod Immunol. 2018; 79 (6): e12838. DOI: 10.1111/aji.12838.

7. Ворошилина Е. С., Зорников Д. Л., Паначева Е. А. Сравнительное исследование микробиоты эякулята методом количественной ПЦР и культуральным методом. Вестник РГМУ. 2019; 1: 44-9. DOI: 10.24075/vrgmu.2019.009.

8. Štšepetova J, Baranova J, Simm J, et al. The complex microbiome from native semen to embryo culture environment in human in vitro fertilization procedure. Reprod Biol Endocrinol. 2020; 18 (1): 3. DOI: 10.1186/s12958-019-0562-z.

9. Рахматулина М. Р., Галкина И. С. Диагностика инфекционной урогенитальной патологии методом количественной ПЦР. Вестник РГМУ. 2019; 6: 114-8. DOI: 10.24075/vrgmu.2019.088.

10. Боровец С. Ю. Диагностическая значимость исследования микрофрлоры эякулята у больных хроническим бактериальным простатитом методом PCR-RT «Андрофрлор». В сборнике: Материалы 5-й научно-практической конференции урологов Северо-Западного федерального округа РФ; СанктПетербург, 2019. Урологические ведомости. 2019; 9: 22-23.

11. Hou D, Zhou X, Zhong X, Settles ML, Herring J, Wang L, et al. Microbiota of the seminal fluid from healthy and infertile men. Fertil Steril. 2013 Nov; 100 (5): 1261-9. DOl: 10.1016/j.fertnstert.2013.07.1991.

12. Tomaiuolo R, Veneruso I, Cariati F, D'Argenio V. Microbiota and Human Reproduction: The Case of Male Infertility. High Throughput. 2020 Apr 13; 9 (2): pii E10. DOI: 10.3390/ht9020010.

13. Altmäe S, Franasiak JM, Mändar R. The seminal microbiome in health and disease. Nat Rev Urol. 2019 Dec; 16 (12): 703-21. DOI:10.1038/s41585-019-0250-y.

14. Рахматулина М. Р., Болдырева М. Н., Липова Е. В., Чекмарев А. С., Галкина И. С.. Оценка микробиоты соскоба уретры у мужчин с инфекциями, передаваемыми половым путем. Урология. 2019; 6: 31-37.

15. Липова Е. В., Чекмарев А. С., Болдырева М. Н. Новый метод диагностики инфекционно-воспалительных заболеваний нижних отделов мочеполового тракта у мужчин (тест «Андрофрлор ${ }^{\oplus}$, «Андрофрлор ${ }^{\oplus}$ Скрин»). М., 2017; 48 с.

16. Почерников Д. Г., Галкина И. С., Постовойтенко Н. Т., Герасимов А. М. Сравнительный анализ биотопа эякулята и цервикального канала методом ПЦР-РВ с тестами «Андросрлор» и «Фемофрлор» в супружеских парах. Вестник
РГМУ. 2017; 2: 37-41. DOI: 10.24075/brsmu.2017-02-05.

17. Баранова Е. Е., Батенева Е. И., Галкина И. С., Донников А. Е., Зорина В. В., Тумбинская Л. В. и др. ПЦР в реальном времени: новые возможности технологии в решении репродуктивных проблем: учебное пособие. М.: ДНК-Технология, 2013; 63 с.

18. Тапильская Н. И., Шахова М. А. Прегравидарная подготовка супружеской пары с участием обоих партнеров при частых рецидивах бактериального вагиноза. Лечащий врач. 2018; 2: 82-87.

19. Чигринец С. В., Брюхин Г. В. Связь микробиоты уретры с качеством эякулята и содержанием эндокринных дисрапторов в семенной жидкости у мужчин. Андрология и генитальная хирургия. 2018; 19 (4): 60-66. DOI: 10.17650/2070-9781-201819-4-60-66.

20. Frølund M, WikstroÈm A, Lidbrink P, Abu Al-Soud W, Larsen N, Harder CB, et al. The bacterial microbiota in first-void urine from men with and without idiopathic urethritis. PLOS ONE 2018; 13 (7): e0201380. DOI: 10.1371/journal.pone.0201380

21. Ivanov IB, Kuzmin MD, Gritsenko VA. Microflora of the seminal fluid of healthy men and men suffering from chronic prostatitis syndrome. Int J Androl. 2009; 32 (5): 462-7. DOI:10.1111/j.13652605.2008.00878.x

22. Baud D, Pattaroni C, Vulliemoz N, Castella V, Marsland BJ, Stojanov M. Sperm Microbiota and Its Impact on Semen Parameters. Front Microbiol. 2019 Feb 12; 10: 234. DOI: 10.3389/ fmicb.2019.00234.

23. Weng SL, Chiu CM, Lin FM, Huang WC, Liang C, Yang T, et al. Bacterial communities in semen from men of infertile couples: metagenomic sequencing reveals relationships of seminal microbiota to semen quality. PLoS One. 2014 Oct 23; 9 (10): e110152. DOI: 10.1371/journal.pone.0110152.

24. Nickel JC. Chronic prostatitis: an infectious disease? Infect Urol. 2000; 13 (2): 31-8.

25. Kogan Ml, Ibishev KS, Cherny AA, Naboka YL, Krakhotkin DV, Krainiy PA, et al/. 244 Analysis of microbiome prostatic secretion in depending of levels total testosterone in blood serum. The Journal of Sexual Medicine. 2018; 15 (7, Suppl 3): 219. DOl: https://doi.org/10.1016/j.jsxm.2018.04.209.

26. Ho C-H, Fan C-K, Yu H-J, Wu C-C, Chen K-C, Liu S-P, et al. Testosterone suppresses uropathogenic Escherichia coli invasion and colonization within prostatecells and inhibits inflammatory responses through JAK/STAT-1 signaling pathway. PLoS One. 2017 Jun 30; 12 (6): e0180244. DOI:10.1371/journal. pone.0180244.

27. Почерников Д. Г., Постовойтенко Н. Т., Галкина И. С., авторы. Способ диагностики нарушений гормонального фона у мужчин. Патент РФ № 2715565. 02.03.2020. Бюл. № 7.

28. Инструкция по применению набора реагентов для исследования микрофрлоры урогенитального тракта мужчин методом ПЦР в режиме реального времени Андрослор ${ }^{\circledast}$ (ООО НПО «ДНК-Технология»). Регистрационное удостоверение № Р3Н 20164490. Доступно по ссылке: http:www.dnatechnology.ru/information/aboutamethod/.

29. WHO laboratory manual for the examination and processing of human semen. 5th edn. Geneva, 2010; 271 p.

30. ЦЦкканов А. Ю., Сатыбалдин Д. О., Семикина С. П. Повышение результативности микробиологического исследования эякулята при диагностике причин мужского бесплодия. Урология. 2019; 6: 26-30. Доступно по ссылке: https://dx.doi. org/10.18565/urology.2019.6.26-30

\section{References}

1. Chaplin AV, Rebrikov DV, Boldyreva MN. The human microbiome. Bulletin of RSMU. 2017; (2): 5-13. DOl: 10.24075/brsmu.2017-02-01.

2. Jungwirth JA, Diemer T, Kopa Z, et. al. EAU guidelines on male infertility (C) European Association of Urology. Available from: https://uroweb.org/wp-content/uploads/EAU-Guidelines-onMale-Infertility-2019.pdf (Accessed May 2, 2019).

3. Shhepleva PA, redaktor. Andrologija dlja urologov. M.: MedforumAl'fa, 2019; 424 s. Russia.

4. Aljaev YuG, Glybochko PV, Pushkar DYu, redaktory. Urologija: Rossijskie klinicheskie rekomendacii. M.: Medforum, 2018; 544 s. Russia

5. Pochernikov DG, Vitvickaja YuG, Boldyreva MN, Galkina IS. 
Informativnost' biomateriala dlja issledovanija mikrobioty urogenital'nogo trakta muzhchin metodom PCR-RV (pilotnoe issledovanie). Jeksperimental'naja i klinicheckaja urologija. 2019; 2: 128-32. DOI: 10.29188/2222-8543-2019-11-2-128-132. Russia.

6. Monteiro C, Marques PI, Cavadas B, et al. Characterization of microbiota in male infertility cases uncovers differences in seminal hyperviscosity and oligoasthenoteratozoospermia possibly correlated with increased prevalence of infectious bacteria. Am J Reprod Immunol. 2018; 79 (6): e12838. DOI: 10.1111/aji.12838.

7. Voroshilina ES, Zornikov DL, Panacheva EA. Evaluation of the ejaculate microbiota by real-time PCR and culture-based technique. Bulletin of RSMU. 2019; 1: 41-6. DOI: 10.24075/ vrgmu.2019.009.

8. Štšepetova J, Baranova J, Simm J, et al. The complex microbiome from native semen to embryo culture environment in human in vitro fertilization procedure. Reprod Biol Endocrinol. 2020; 18 (1): 3. DOI: 10.1186/s12958-019-0562-Z.

9. Rakhmatulina MR, Galkina IS. Quantitative PCR in diagnosing infectious urogenital pathology. Bulletin of RSMU. 2019; 6: 10710. DOI: $10.24075 /$ vrgmu.2019.088.

10. Borovec SYu. Diagnosticheskaja znachimost' issledovanija mikroflory jejakuljata u bol'nyh hronicheskim bakterial'nym prostatitom metodom PCR-RT «Androflor». V sbornike: Materialy 5-j nauchno-prakticheskoj konferencii urologov Severo-Zapadnogo federal'nogo okruga RF; Sankt-Peterburg, 2019. Urologicheskie vedomosti. 2019; 9: 22-23. Russia.

11. Hou D, Zhou X, Zhong $X$, Settles ML, Herring J, Wang L, et al. Microbiota of the seminal fluid from healthy and infertile men. Fertil Steril. 2013 Nov; 100 (5): 1261-9. DOI: 10.1016/j.fertnstert.2013.07.1991.

12. Tomaiuolo R, Veneruso I, Cariati F, D'Argenio V. Microbiota and Human Reproduction: The Case of Male Infertility. High Throughput. 2020 Apr 13; 9 (2): pii E10. DOI: 10.3390/ht9020010.

13. Altmäe S, Franasiak JM, Mändar R. The seminal microbiome in health and disease. Nat Rev Urol. 2019 Dec; 16 (12): 703-21. DOI:10.1038/s41585-019-0250-y.

14. Rakhmatulina MR, Boldyreva MN, Lipova EV, Chekmarev AS, Galkina IS. Ocenka mikrobioty soskoba uretry u muzhchin s infekcijami, peredavaemymi polovym putem. Urologija. 2019; 6: 31-37. Russia.

15. Lipova EV, Chekmarev AS, Boldyreva MN. Novyj metod diagnostiki infekcionno-vospalitel'nyh zabolevanij nizhnih otdelov mochepolovogo trakta u muzhchin (test Androflor ${ }^{\oplus}$, Androflor ${ }^{\oplus}$ Skin). M., 2017; 48 s. Russia.

16. Pochernikov DG, Galkina IS, Postovoytenko NT, Gerasimov AM. A comparative analysis of seminal and vaginal microbiota of married couples by real-time PCR with Androflor and Femoflor reagent kits. Bulletin of RSMU. 2017; 2: 34-39. DOI: 10.24075/ brsmu.2017-02-05.

17. Baranova EE, Bateneva El, Galkina IS, Donnikov AE, Zorina WV, Tumbinskaja LV, i dr. PCR v real'nom vremeni: novye vozmozhnosti tehnologii v reshenii reproduktivnyh problem: uchebnoe posobie. M.: DNK-Tehnologija, 2013; 63 s. Russia.
18. Tapilskaja NI, Shahova MA. Pregravidarnaja podgotovka supruzheskoj pary s uchastiem oboih partnerov pri chastyh recidivah bakterial'nogo vaginoza. Lechashhij vrach. 2018; 2: 8287. Russia.

19. Chigrinec SV, Brjuhin GV. Svjaz' mikrobioty uretry $s$ kachestvom jejakuljata i soderzhaniem jendokrinnyh disraptorov v semennoj zhidkosti u muzhchin. Andrologija i genital'naja hirurgija. 2018; 19 (4): 60-66. DOI: 10.17650/2070-9781-2018-19-4-60-66. Russia.

20. Frølund M, Wikstroł̀m A, Lidbrink P, Abu Al-Soud W, Larsen N, Harder CB, et al. The bacterial microbiota in first-void urine from men with and without idiopathic urethritis. PLoS ONE 2018; 13 (7): e0201380. DOI: 10.1371/journal.pone.0201380.

21. Ivanov IB, Kuzmin MD, Gritsenko VA. Microflora of the seminal fluid of healthy men and men suffering from chronic prostatitis syndrome. Int J Androl. 2009; 32 (5): 462-7. DOI:10.1111/j.13652605.2008.00878.x.

22. Baud D, Pattaroni C, Vulliemoz N, Castella V, Marsland BJ, Stojanov M. Sperm Microbiota and Its Impact on Semen Parameters. Front Microbiol. 2019 Feb 12; 10: 234. DOI: 10.3389/ fmicb.2019.00234.

23. Weng SL, Chiu CM, Lin FM, Huang WC, Liang C, Yang T, et al, Bacterial communities in semen from men of infertile couples: metagenomic sequencing reveals relationships of seminal microbiota to semen quality. PLoS One. 2014 Oct 23; 9 (10): e110152. DOI: 10.1371/journal.pone.0110152.

24. Nickel JC. Chronic prostatitis: an infectious disease? Infect Urol. 2000; 13 (2): 31-8.

25. Kogan MI, Ibishev KS, Cherny AA, Naboka YL, Krakhotkin DV, Krainiy PA, et al/. 244 Analysis of microbiome prostatic secretion in depending of levels total testosterone in blood serum. The Journal of Sexual Medicine. 2018; 15 (7, Suppl 3): 219. DOl: https://doi.org/10.1016/j.jsxm.2018.04.209.

26. Ho C-H, Fan C-K, Yu H-J, Wu C-C, Chen K-C, Liu S-P, et al. Testosterone suppresses uropathogenic Escherichia coli invasion and colonization within prostatecells and inhibits inflammatory responses through JAK/STAT-1 signaling pathway. PLoS One. 2017 Jun 30; 12 (6): e0180244. DOl:10.1371/journal. pone. 0180244

27. Pochernikov DG, Postovojtenko NT, Galkina IS, avtory. Sposob diagnostiki narushenij gormonal'nogo fona u muzhchin. Patent RF \# 2715565. 02.03.2020. Bjul. \# 7. Russia.

28. Instrukcija po primeneniju nabora reagentov dlja issledovanija mikroflory urogenital'nogo trakta muzhchin metodom PCR v rezhime real'nogo vremeni Androflor (OOO NPO "DNK-Tehnologija»). Registracionnoe udostoverenie \# RZN 20164490. Available from: http:www.dna-technology.ru/information/aboutamethod/. Russia.

29. WHO laboratory manual for the examination and processing of human semen. 5th edn. Geneva, 2010. 271 p.

30. Cukanov AYu, Satybaldin DO, Semikina SP. Povyshenie rezul'tativnosti mikrobiologicheskogo issledovanija jejakuljata pri diagnostike prichin muzhskogo besplodija. Urologija. 2019; 6: 26-30. Available from: https://dx.doi.org/10.18565/urology.2019.6.26-30. Russia. 